\title{
Recent Research on the Telemorase Enzyme and the Concept of Immortality
}

\author{
Omar Alfi, MD, and Mazin Elhadary \\ Alfi Stem Cell Research and Education Foundation \\ Pasadena, California
}

\begin{abstract}
:
During DNA replication, telomeres at the tips of chromosomes maintain connections that allow orderly replication. With each division, the telomere shortens until it gradually reaches a critical length that prohibits the cell from further division, causing several diseases associated with senility. Telomerase is an enzyme found in germ cells and embryonic stem cells that helps replace the telomeres. Through processes that reactivate these telomerases, scientists hope to develop regenerative methods to significantly extend the human life span. The process of telomerase activation, on the other hand, may create cancer cells, and understanding telomerase inhibition could help in combating cancer. From an Islamic perspective, the life span of a human, which only God determines, should be spent promoting good for society and preventing what is bad. If antiaging measures help maintain the productivity of an individual, and if that individual's productivity is good for society, then antiaging measures are good. Religious organizations and governments would need to promote social justice in balancing resources needed by younger and older generations.
\end{abstract}

Key words: telomere, telomerase, regenerative medicine, cancer cell, immortality, Islam, antiaging.

Presented at the International Seminar on Human Genetic and Reproductive Technologies: Comparing Religious and Secular Perspectives, organized by the Islamic Organization for Medical Sciences, Kuwait, in collaboration with the World Health Organization (Eastern Mediterranean Office); the Islamic Medical Educational, Scientific and Cultural Organization; and the Council for International Organizations of Medical Services in Cairo, Egypt, on February 6, 2006.

Correspondence should be directed to O. Alfi, MD, 11 W. Del Mar Boulevard Pasadena, California 91105 email:genetics11@aol.com fax: (818) 952-1914
Introduction

$\mathrm{H}$ uman cells contain 23 pairs of chromosomes, which carry the genes that characterize and control the functions of the cell. The genes are coded according to nucleotide pairs, arranged on the DNA double strand in a unique way for the species (human) and for the individual (molecular fingerprinting). As the living cells replicate, the double strands separate, and each becomes a template for a new DNA strand, allowing the original doublestranded DNA to become two identical double strands, one for each of the two daughter cells. To regulate this process, the double strand of the original cell maintains connection through the tips of the chromosome so that the new double strands maintain a relationship with each other. The mechanism 
that maintains that relationship is a DNA cap at the two terminal ends of the chromosomes. It is formed of noncoding pairs of nucleotides (approximately 20,000 each) that share in holding the two new daughter double strands together. Each cap is termed a "telomere." In the process of cell division, the telomere loses a few hundred pairs of nucleotides, but the major portion of the telomere remains intact and helps in the future divisions of the cell. However, with each cycle, the telomere becomes slightly shorter. As life continues, the telomere gradually gets shorter and shorter until a critical level is reached, prohibiting the cell from any further division. Once this cell dies, it can no longer be replaced. Depending on the type of these cells, their functions cannot be carried out anymore, and diseases associated with a loss in tissue viability start to occur. ${ }^{1}$ In humans these include Alzheimer's disease, Parkinson's disease, and heart attacks. These are usually related to senility due to the fact that the cells have undergone numerous cell division cycles, causing a loss in telomeres. If there is a way to maintain the length of the telomere, these senility disorders could be prevented. ${ }^{2}$ The function of the brain, heart, muscles, and other organs would be maintained, resulting in a healthier, longer life.

The enzyme that helps form or replace the telomeres is called "telomerase." In humans, this enzyme is only present and functioning in the germ cell (egg and sperm), the resulting embryonic stem cells of the developing fetus, and some regenerating tissues. Certain drug companies are investing in products that reactivate this enzyme beyond the early fetal life. ${ }^{3}$

If this happens, together with the recent great progress in health care and in the new discipline of regenerative medicine, the average survival of humans is expected to increase significantly well beyond the age of 70 years (one generation ago in the western world) and the current life expectancy of 100 years for the new generation. ${ }^{4}$ However, telomere lengthening does not necessarily ensure a life span extension, and telomerase activation should raise a red flag for potential cancer development. ${ }^{2}$

Normally, some cells' DNA may acquire damage that creates a cancerous cell. In many or most of these cells, the telomerase enzyme that was inactive since fetal life is reactivated. This cancer cell, with reactivated telomerase, can make the cell rebuild the portion of the telomere that is lost with every divi- sion, causing the cell to continue dividing for very long periods without aging or dying. ${ }^{5}$ In some cancer cells, the telomerase level is directly related to prognoses. Some of these cancer cells have continued to grow in tissue cultures and have for years outlived the individual in whom they started. ${ }^{6}$ In a sense, these cancer cells can achieve "immortality" in the laboratory.

If we can turn off that telomerase in the cancer cell, the telomere cannot regenerate and will continue to deplete with every cell division until the cell dies, ${ }^{7}$ creating a situation where telomerase inhibition is an attractive treatment for cancer therapy. On the other hand, telomerase stimulation is attractive for expanding the potential of cellular proliferation with delay in senility and improving tissue regeneration. ${ }^{2}$ A combination of both objectives, i.e. stimulating telomerase in body cells without causing cancer, would be optimal. This is currently a major goal for several research and drug companies. A concern that should be initially addressed is that the design of the human body may not be able to cope with an extended life span. Eventually, this could be compensated for as regenerative technology further develops. However, current telomere technology is far from a stage where it can be applied to actually extend the human life span. Recently, progress has occurred in both directions, and scientists are trying to answer the question: Is the telomerase gene an immortality gene or an oncogene?

Approaches of researchers to activate the telomerase include administering drugs and infecting the body with viruses that carry the active gene but do not harm the cells. The direction is promising, and firms have already claimed some success to the extent that California voters in 2005 approved a \$3billion bond to start a California institute of regenerative medicine, which includes research on aging, tissue repair, stem cells, and telomerase.

\section{What are the Implications? Religion}

From the point of view of religion, there is no immortality for humans in this life:

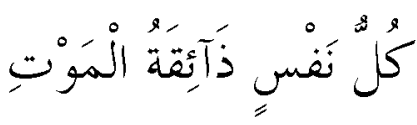

Every soul shall have a taste of death ...8 Some may wish to survive 1000 years: 


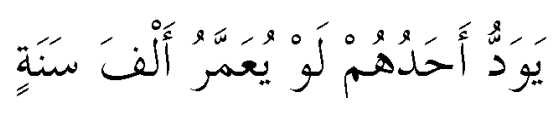

... Each one of them wishes He could be given a life of a thousand years ...9

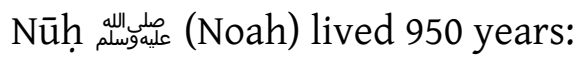

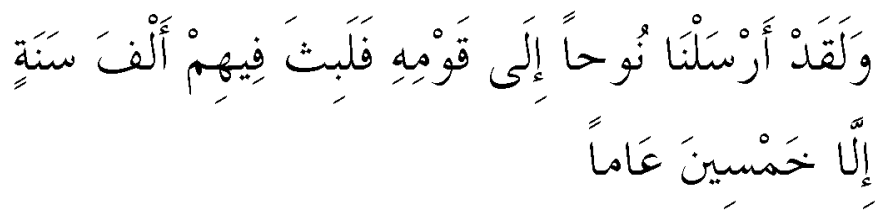

We (once) sent Noah to his people, and he tarried among them a thousand years less fifty ...10

The issue is not how long one lives but how much good one does.

\section{Society}

The impact on society would be far-reaching. Overpopulation is expected, resulting in a burden on resources. The benefit of greater productivity of longer-living experts may offset these challenges. In any event, major changes in the education system would be necessary.

\section{Ethics}

These developments would raise significant ethical issues. This technology would not be available to poor societies or countries, nor would it be available to the poor in affluent societies and countries, thus widening the gap between the first and third worlds and causing a new unprecedented class to emerge. More resources would be used by a smaller percentage of the population, both within nations and throughout the world.

\section{Discussion}

We have reviewed the topic of telomerase enzyme as an approach to immortality of the cells and probably as a future means of delaying aging. The enzyme is usually referred to as the "enzyme of immortality." Though the issue of immortality in humans is not considered literally, research in the area has created great interest, writings, and debates in ethics and among some religious groups. New corporations have started. Among them is the Immortality Institute (ImmInst.org), which deals with the wide variety of issues regarding antiaging approaches. A Google internet search for telomerase finds about 850,000 links; a search on telomerase and immortality finds about 50,000 matches.

Antiaging medicine is important for individuals and societies. In Islam, "doing good" is an imperative. Muslims are required to promote what is good for society and prevent what is bad and to compete in doing that. If antiaging measures help maintain the productivity of an individual, and if that individual's productivity is good for society, then the antiaging measures are good. Otherwise, antiaging measures would not, or should not, be desirable. The Qur'an mentions that someone may wish to survive for 1000 years, but that would not shelter him or her from hell fire if what they are doing is evil. ${ }^{9}$ So, longevity in itself is not beneficial if it is not associated with doing good in a society.

The length of the life of an individual cannot be predicted, and only God all knows when an individual is to die. However, with improvements in healthcare over the past several decades, the average survival of Western populations increased from 40 years to 50 , 60 , and 70 at the present time. With the rapid pace of healthcare improvements, the survival of the new generation is expected to be 100 years, especially with the developments in regenerative medicine and in stem-cell technology. The new progress in telomerase research may push the age more towards that "relative immortality" age of 150 or more. For a Muslim, relative immortality may be realized only if God alle wants it to be. An interesting point to mention is that the Qur'an states that prophet Noah aلd lived for 950 years. ${ }^{10}$

Antiaging genetic technologies would impact the relationship between individuals and society through the actions of the individual. For example, if the individual's actions are good, carried over a longer life, the result is good. If an individual's actions are evil, carried over longer life, it is bad for the society.

We may direct our discussion to the appropriate use of limited resources. Throughout life, those who can afford something try to get it, and those who cannot will not, especially when resources are scarce. In general, longevity leads to more resources being committed to the increasing numbers of older people. This may put pressure on resources needed for the younger growing generation, whether in food, health care, housing, transportation, etc. If there is enough 
for all, there is no harm, but the expectation would be that the aging population will take away some resources from the younger and underprivileged population, and that is a problem. Even if an advanced, wealthy nation can afford to provide the extra resources for the aged, most likely that will be at the expense of resources that should help a third world nation, and there would be greater inequity within a nation and between nations. The main balancing mechanism would be promoting social justice as encouraged by religions and governments.

There is always concern that genetic technologies may lead to a new form of eugenics in which the disabled are gradually eliminated. This should never happen. We should try to eliminate the disability not the disabled. A hopeful model for that would be the direction to treat fetal disorders by fetal constructive treatments and the growing fetal stem cell technology instead of resorting to termination of pregnancy.

\section{References}

1. Espejel S, Klatt P, Menissier-de Murcia J, et al. Impact of telomerase ablation on organismal viability, aging, and tumorigenesis in mice lacking the DNA repair proteins PARP-1, Ku86, or DNA-PKcs. J Cell Biol. 2004;167(4):627-38.

2. Wright WE, Shay JW. Telomere biology in aging and cancer. J Am Geriatr Soc. 2005;53(9 supp):S292-4. 3. Olaussen KA, Dubrana K, Domont J, et al. Telomeres and telomerase as targets for anticancer drug development. Crit Rev Oncol Hematol. 2006;57(3):191-214. 4. Hertzog RG. Ancestral telomere shortening: a countdown that will increase mean life span? Med Hypotheses. 2004;67(1):157-60.

5. Shin JS, Hong A, Solomon MJ, et al. The role of telomeres and telomerase in the pathology of human cancer and aging. Pathology. 2006;38(2):103-13.

6. Ivankovic M, Cukusic A, Gotic I, et al. Telomerase activity in HeLa cervical carcinoma cell line proliferation. Biogerontology. 2007;8:163-72.

7. Weise JM, Gunes C. Telomeres and telomerase. A survey about methods and recent advances in cancer diagnostic and therapy. Histol Histopathol. 2006;21(11):1249-61.

8. Glorious Qur'an, Chapter 3, Verse 185.

9. Glorious Qur'an, Chapter 2, Verse 96.

10. Glorious Qur'an, Chapter 29, Verse 14. 